The Editors welcome topical correspondence from readers relating to articles published in the fournal. Letters should be submitted electronically via the B7S submission site (mc.manuscriptcentral.com/bjs). All correspondence will be reviewed and, if approved, appear in the fournal. Correspondence must be no more than 300 words in length.

\section{Abdominal fluid samples (negative for SARS-CoV-2) from a critically unwell patient with respiratory COVID-19}

\section{Editor}

The ongoing COVID-19 outbreak is taking its toll on healthcare systems and their workers worldwide ${ }^{1,2}$. As a result, elective procedures have been put on hold indefinitely in efforts to prevent hospitals from being overwhelmed with patients. Nevertheless, the need to perform emergency surgery and care for high priority surgical patients remains ${ }^{1,2}$. This applies not only for SARS-CoV-2-negative patients, but even more so for SARS-CoV-2-positive patients due to their escalating number; including those who are asymptomatic or become secondarily positive during their hospital stay ${ }^{3}$. Despite current knowledge indicating that SARS-CoV-2 spreads mainly through respiratory droplets, it is entirely unclear if SARSCoV-2 can spread to the peritoneal cavity or other bodily fluids ${ }^{4}$. This is especially relevant for surgery involving electrocautery, lasers or ultrasonic scalpels because viruses (including hepatitis $\mathrm{B}$, hepatitis $\mathrm{C}$ and human immunodeficiency virus) spread through gaseous by-products commonly referred to as 'surgical smoke'.

Abdominal fluid (ascites), bile, liver and gall bladder samples were collected during emergency cholecystectomy of a critically ill patient suffering from COVID-19. Tracheal secretion and throat swab samples were collected immediately prior to surgery as positive controls. All samples were tested for SARS-CoV-2 by real-time reverse transcriptase polymerase chain reaction (PCR) using validated primers ${ }^{5}$. PCR tests revealed strongly positive results for SARS-CoV-2 RNA in tracheal secretion as well as in throat swab samples, with cycle threshold values of 20 and 25, respectively. The remaining samples all tested negative for SARSCoV-2 suggesting that the virus does not spread to the abdominal cavity, bile and abdominal organs. A stool sample obtained one day after surgery also tested negative.

These preliminary findings suggest that the potential infectious risk for operating theatre staff and surgeons during open and laparoscopic operations in SARS-CoV-2 patients is lower than initially expected ${ }^{3}$.

\section{S. Flemming ${ }^{1}$, M. Hankir ${ }^{1}$, I. Hering ${ }^{1}$, P. Meybohm ${ }^{3}$, M. Krone ${ }^{4}$, \\ B. Weissbrich ${ }^{5}$, C.T. Germer ${ }^{1}$ and \\ A. Wiegering ${ }^{1,2}$ (D) \\ ${ }^{1}$ Department of General, Visceral, \\ Transplant, Vascular and Paediatric \\ Surgery, University Hospital Wuerzburg, and ${ }^{2}$ Department of Biochemistry and \\ Molecular Biology, ${ }^{3}$ Department of Anaesthesia and Critical Care, ${ }^{4}$ Institute for Hygiene and Microbiology, and ${ }^{5}$ Institute for Virology and \\ Immunobiology, University of Wuerzburg, Wuerzburg, Germany \\ DOI: $10.1002 / b j s .11713$}

1 COVIDSurg Collaborative. Global guidance for surgical care during the COVID-19 pandemic. Br 7 Surg 2020; https://doi.org/10.1002/bjs.11646 [Epub ahead of print].

2 Spinelli A, Pellino G. COVID-19 pandemic: perspectives on an unfolding

Fig. 1 SARS-CoV-2 is detectable in the respiratory system but not in gastrointestinal samples

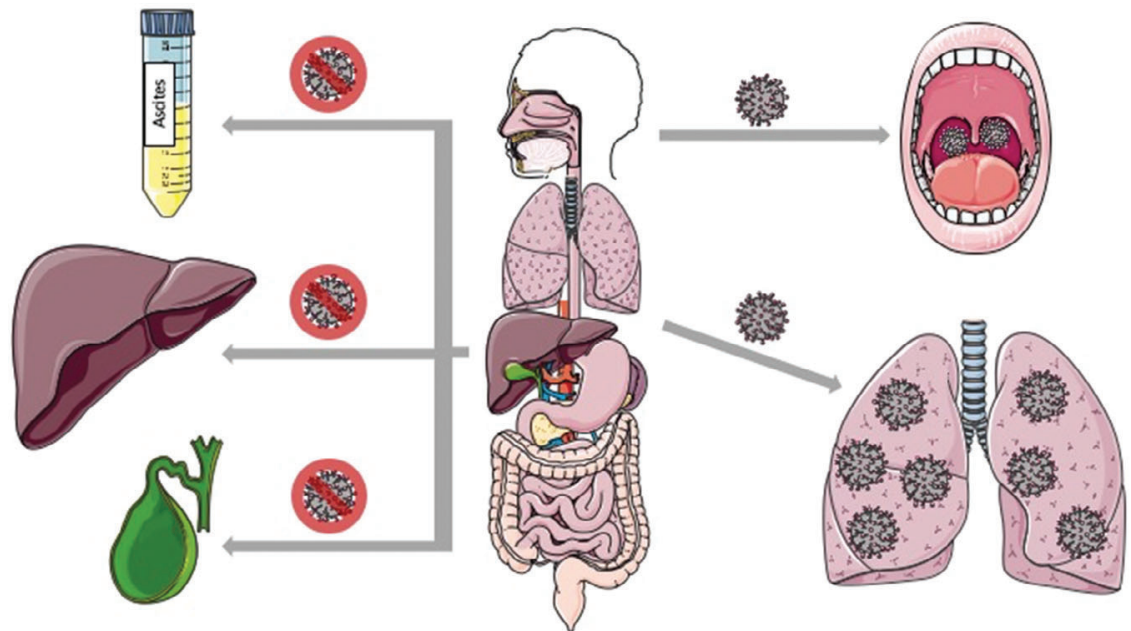

Created with the support of SMART Servier Medical Art (smart.servier.com). 
crisis. Br 7 Surg 2020; https://doi.org/ 10.1002/bjs.11627 [Epub ahead of print].

3 Di Marzo F, Sartelli M, Cennamo R, Toccafondi G, Coccolini F, La Torre G et al. Recommendations for general surgery activities in a pandemic scenario (SARS-CoV-2). Br 7 Surg 2020; https://doi.org/10.1002/bjs .11652 [Epub ahead of print].
4 World Health Organization. Modes of transmission of virus causing COVID-19: implications for IPC precaution recommendations; 2020. https://www .who.int/news-room/commentaries/ detail/modes-of-transmission-of-viruscausing-covid-19-implications-for-ipcprecaution-recommendations [accessed 22 April 2020].
5 Corman VM, Landt O, Kaiser M, Molenkamp R, Meijer A, Chu DK et al. Detection of 2019 novel coronavirus (2019-nCoV) by real-time RT-PCR. Euro Surveill 2020; 25. https://doi.org/ 10.2807/1560-7917.ES.2020.25.3 .2000045 . 